\title{
Shotgun Sequencing
}

National Human Genome Research Institute (NHGRI)

\section{Source}

National Human Genome Research Institute (NHGRI). Shotgun Sequencing.

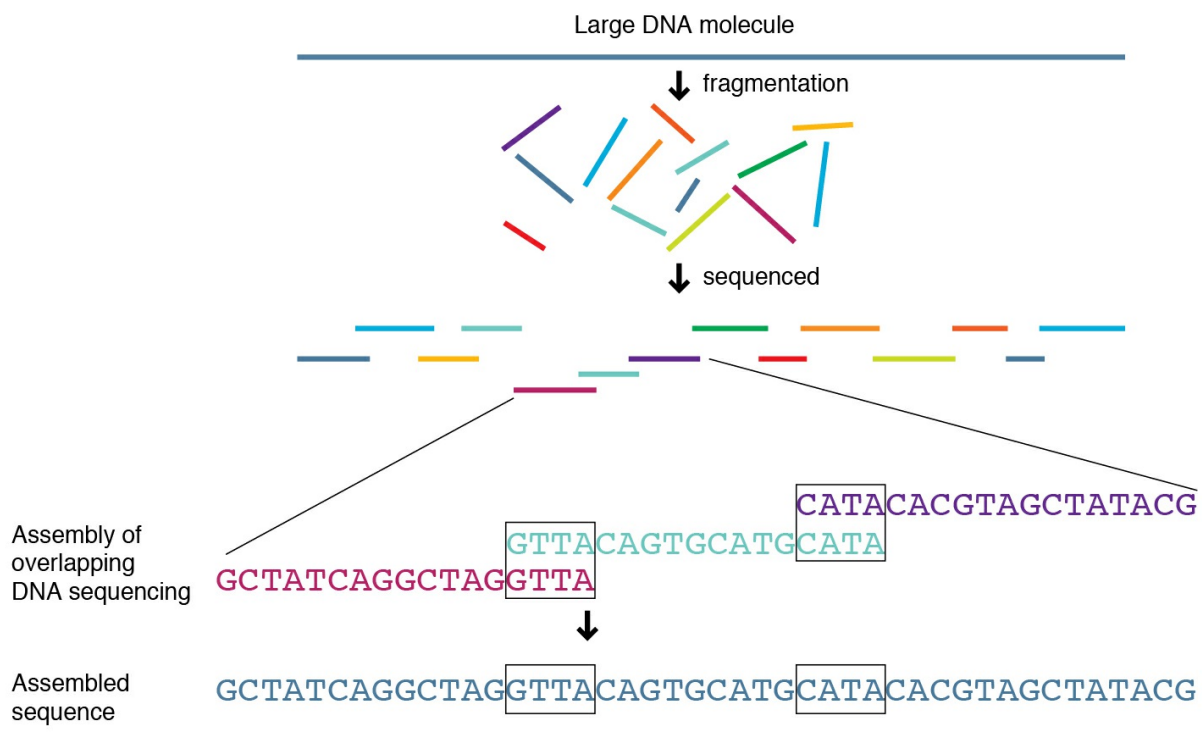

Shotgun sequencing is a laboratory technique for determining the DNA sequence of an organism's genome. The method involves breaking the genome into a collection of small DNA fragments that are sequenced individually. A computer program looks for overlaps in the DNA sequences and uses them to place the individual fragments in their correct order to reconstitute the genome. 